Research Article

\title{
Intelligent Prediction Method for Operation and Maintenance Safety of Prestressed Steel Structure Based on Digital Twin Technology
}

\author{
Zhansheng Liu $(\mathbb{D}$, Antong Jiang, Anshan Zhang, Zezhong Xing, and Xiuli Du \\ Key Laboratory of Urban Security and Disaster Engineering of Ministry of Education, Beijing University of Technology, \\ Beijing 100124, China \\ Correspondence should be addressed to Zhansheng Liu; lzs4216@163.com
}

Received 23 November 2020; Revised 27 February 2021; Accepted 10 April 2021; Published 23 April 2021

Academic Editor: Wen Yi

Copyright $(2021$ Zhansheng Liu et al. This is an open access article distributed under the Creative Commons Attribution License, which permits unrestricted use, distribution, and reproduction in any medium, provided the original work is properly cited.

The operation and maintenance stage of the long-span prestressed steel structure is the core link of the whole life cycle. At present, there are few studies on the change law of safety risk in the whole process of operation and maintenance, especially the research on the analysis and prediction of the change law of safety risk in the whole process of structural operation and maintenance by effectively using the abundant monitoring data and relevant safety risk information in the operation and maintenance stage, which also affects the prestressed steel, which also affects the efficiency of judgment and control decision-making of operation and maintenance safety state of prestressed steel structure. Taking the spoke-type cable truss as an example, this paper proposes a new concept of integrating the digital twin model (DTM) with steel structure operation and maintenance safety. Through the combination of real physical space dimensions and digital virtual space dimensions, it is based on a hypothetical analysis model. In the above, a theoretical framework is proposed, and a case analysis of a prestressed steel structure is carried out from big data, and the feasibility of applying this method in the prestress loss and uneven rain and snow load conditions is evaluated. This method can provide guidance for operation and maintenance management and formulate strategies in time.

\section{Introduction}

In recent years, China is changing from a big construction country to a strong construction country. Although it has created remarkable construction achievements, there are still many problems in the operation and maintenance management of the construction industry. Most of the project management modes are in remedial maintenance management, which needs to be deeply integrated with the new generation of information technology to improve the level of intelligent security management. In 2016, the Ministry of Housing and Urban-Rural Development issued the "2016-2020 construction industry informatization development outline" to clearly put forward: "combined with the application of BIM and other new technologies, focus on improving the information standard system of construction engineering survey and design, construction, operation and maintenance life cycle, and lay the foundation for information resource sharing and in-depth mining." In 2017, the new generation of artificial intelligence development plan issued by the State Council clearly pointed out that "by 2025, artificial intelligence will become the main driving force for China's industrial upgrading and economic transformation." From this point of view, based on BIM, big data, and intelligence and other technologies, it provides new policy power for the intelligent development and safety control of the construction industry.

Due to reasonable stress and strong practicability, a large-span prestressed steel structure has been widely used in national key projects such as stadiums, exhibition centers, and transportation hubs [1]. Cables are the key and fragile structural members in prestressed steel structures. At the same time, in the cable operation and maintenance stage, the change of cable force is usually used to evaluate the safety 
status of the structure and is considered an important safety index [2]. In the operation and maintenance stage, once the cable is broken, local collapse or overall damage and other major safety accidents will often appear in the structure. Therefore, cable safety monitoring and real-time prediction and early warning have become the key elements in the operation and maintenance stage of prestressed steel structure [3]. The traditional operation and maintenance safety management of prestressed steel structure has the disadvantages of static information, weak risk correlation, and low intelligent degree, which cannot realize the prediction and control of cable operation and maintenance safety risk with time and space fluctuation. Therefore, it is necessary to provide an intelligent safety risk prediction and control method considering multifactor coupling [4]. Therefore, how to establish a predictive control model which can accurately reflect the safety status of structure operation and maintenance and update data in real time is an urgent problem to be solved. For this reason, many scholars have introduced information technology. Zhou and Wang [5] analyzed the problems existing in the operation and maintenance management process of existing bridges and studied the application value of BIM technology to the operation and maintenance management of existing bridges. Relying on the steel structure canopy, Li et al. [6] introduced an E-BIM structure based on BIM technology for visual monitoring and developed a visual monitoring module suitable for the operation and maintenance management system of large-span empty platform canopy. To sum up, although the existing research methods can achieve the safety evaluation of steel structure in the operation and maintenance stage to a certain extent, the data relatively lack predictability, and the mapping relationship in a virtual environment is lacking, so the safety assessment of in-service prestressed steel structure may not be ideal.

On the other hand, with the continuous development of emerging technologies (such as cloud computing, Internet of Things, and big data) and the vigorous promotion of industrial informatization, the application of the digital twin concept to realize the interaction and integration of manufacturing physical world and information world is one of the research hotspots of intelligent manufacturing concept and goal in the practice of industrial complex system at home and abroad.

The term "digital twin" was formally proposed by Professor Michael Grieves of the University of Michigan in 2003. It refers to a new technology that combines the digital information of a certain device with the real-time data stream obtained during the operation. It is a digital copy or virtual copy of a real entity. It is mainly used for the simulation, optimization, and verification of the virtual space of the product life cycle. In order to ensure that the final product has good geometric quality, the digital twin concept stage is developed and used in product and production system design [7]. In recent years, digital twin technology has made great progress and has been widely used. For example, Warwick [8] applied DT (digital twin) technology to its GE90 engine, which significantly reduced the number of engine overhauls and minimized the premature replacement of spare parts. The use of DT technology has saved tens of millions of dollars. As a global leading IT research and consulting company, Gartner has listed digital twin as one of the top ten strategic technology development trends of that year for four consecutive years (2016-2019). According to Gartner's prediction, by 2021, more than half of the leadingedge industrial companies will adopt and rely on DT technology [9].

Scholars at home and abroad are committed to applying the concept of digital twin to the research of product life cycle. Tao et al. $[10,11]$ proposed a new product design method to drive manufacturing and service by digital twin. Schleich et al. [12] designed a comprehensive digital twin reference model for the whole life cycle of products, which is used for the application of physical products in design and production engineering. Tuegel et al. [13] discussed how the digital twin technology can be used to predict the life of aircraft structures and described in detail the technical challenges faced by the development and application of digital twin technology. Ye et al. [14] proposed a digital twin framework to track the life of spacecraft structures, and with the structural life of the spacecraft quantified by the framework, mission success rates for repeated flights can be maximized at a lower cost. Leser et al. [15] focused on the implementation of DT for the health management of fatigue critical structures, and the DT concept has the potential to revolutionize the way systems and their components are designed, managed, maintained, and operated across a vast number of fields from engineering to healthcare. Mondoro and Grisso [16] demonstrated the use of strain gauge data coupled with a global finite element model and a fatigue damage assessment model to provide information pertinent to maintenance and life cycle decisions for naval ship structures. Zheng et al. [17] summarized the related research of digital twin technology and proposed the application framework of product life cycle management. Through the analysis of the DT model, the realtime status of the actual equipment can be obtained. With the improvement of simulation software, hardware, and computer processing speed, as well as the emergence of the Internet of Things, the wide application of DT technology becomes possible. Different from traditional simulation technology and CAE (Computer-Aided Engineering) technology, DT technology can provide dynamic and constantly changing images according to historical data and current data and can digitally map physical entities in the real world [18].

As a key concept to solve the problem of Information Physics integration, digital twin has been widely concerned and studied by the academic community, and this concept has been gradually applied in the construction industry. Shu et al. [19] provided faster and more accurate procedures to capture the spatial information required by a digital twin of a concrete structure using 3D point cloud data. Zandi et al. [20] propose a framework for the digital twin of infrastructure. The proposed framework is based on the optimized integration of (1) structural inspection, (2) damage quantification, and (3) 
performance prediction. Khajavi et al. [21] studied the expansion of the digital twin in including building life cycle management and explored the benefits and shortcomings of such implementation. Scholar Ye et al. [22] took two railway bridges in Staffordshire, UK, as examples and created a bridge digital twin model for structural health monitoring. Tygesen et al. [23] proposed a novel method for evaluating and improving the performance of digital twin bearings, which is used to predict the fatigue life of offshore structures. Sivalingam et al. [24] accurately predicted the damage accumulation and remaining service life of offshore wind turbine power converter in the work of digital twin framework based on physical methods. Shim et al. [25] discussed how to apply the concept of the digital twin model to the maintenance management of cable-stayed bridges. Lin et al. [26] proposed a digital twin-based collapse fragility assessment method for long-span cable-stayed bridges under strong earthquakes. Three finite element (FE) models of the bridge, including a design document-based FE model, a linearly updated FE model, and a nonlinearly updated FE model, are established to demonstrate the necessity of the digital twin-based assessment. Scholar Liu et al. [27] proposed a digital twin-driven dynamic guidance method for fire evacuation, which realized the real-time collection of environmental information, threedimensional visualization of indoor layout, fire alarm, indoor personnel positioning, evacuation route planning, and other functions. In another study of the author [28], through the establishment of a multi-dimensional digital twin model of prestressed steel structure, using relevant structural historical data to train support vector machines and prediction models, a good evaluation and prediction model was obtained.

In summary, the typical characteristics of digital twin, such as precise mapping and virtual-real interaction, are accelerating the development of application innovation in various industries and also provide the possibility for the transformation and upgrading of intelligent operation and maintenance safety management. It is understood that the cost and time of the operation and maintenance stage of buildings account for more than $70 \%$ of the whole life cycle, while the digital twin technology is rarely used in the operation and maintenance stage of prestressed steel structure, so it is necessary to carry out further exploratory research on the digital twin technology in the operation and maintenance stage of steel structure.

Based on the deficiency of previous research studies on the problems existing in the operation and maintenance stage of prestressed steel structures and the status quo of digital twin theory research, and considering the complexity and diversity of safety risks, this paper analyzes the case of spoke cable truss and proposes a typical structural health prediction system driven by digital twin. Through the combination of real physical space dimension and digital virtual space dimension and finite element analysis (FEA) of the DT model, a theoretical framework is put forward and a case study of a prestressed steel structure is carried out. The feasibility of applying this method in the case of prestress loss and uneven rain and snow load is evaluated, and the fatigue life of each component in the structure is predicted.

\section{Intelligent Prediction Method Based on Digital Twin}

With the acceleration of the transformation and upgrading demand of traditional industries, digital twin will play a more important role in more fields. But this technology is less applied in the field of structure operation and maintenance, especially the direction of safety operation and maintenance of prestressed steel structure. During the operation and maintenance of prestressed steel structure, its members will change, which makes it more difficult to determine the influence of load combination on the components of the whole structure. Based on the digital twin technology, through the data recording and storage and analysis of a few sensors, the system can provide real-time stress, strain, and safety status of the whole structure during the operation and maintenance process. It can evaluate the real-time safety status of steel structure in the operation and maintenance stage and intelligently predict the fatigue condition and remaining life of the steel structure, so as to realize the maintenance of the prestressed steel structure. Therefore, it is a reasonable and efficient solution to apply digital twin technology to structural state monitoring, predictive maintenance, and life cycle management.

\subsection{Structural Health Prediction Framework Driven by} Digital Twins. According to the main characteristics of the digital twin model, users can get as much information as possible about the current state and future behavior of physical twins. In this paper, the functional level of digital twins in the structural operation and maintenance phase is established. As shown in Figure 1, digital twins currently have five levels, starting from the real physical world, to level 1 , and then to level 4; each level contains all the functions of the previous level. In fact, the three key requirements of digital twin, namely, supervision, learning, and decisionmaking, are realized from 2 to 4 levels, respectively.

The database for structural health monitoring operation and maintenance based on the digital twin concept supports multidepartmental and multidisciplinary collaboration for operation and maintenance. Level 1 is the real-time status monitoring. The digital twin platform collects and visualizes state data such as working temperature, working environment, and stress distribution of structural components in real time to ensure the reliability of equipment state monitoring. Level 2 is fault diagnosis, which conducts diagnosis and analysis based on the actual value exceeding the set warning value. Level 3 is prediction, which efficiently processes the massive data accumulated in history and generates O\&M models based on intelligent algorithms to diagnose the probability and time of failure of products under different usage conditions. Level 4 is maintenanceassisted decision-making, based on fault prediction results, to assist in the formulation of maintenance plans and remotely guide engineers to perform on site, effectively avoiding the problem of missing information transmission.

The key distinguishing feature of digital twins (the dividing line between level 2 and level 3 in Figure 1) is that it 


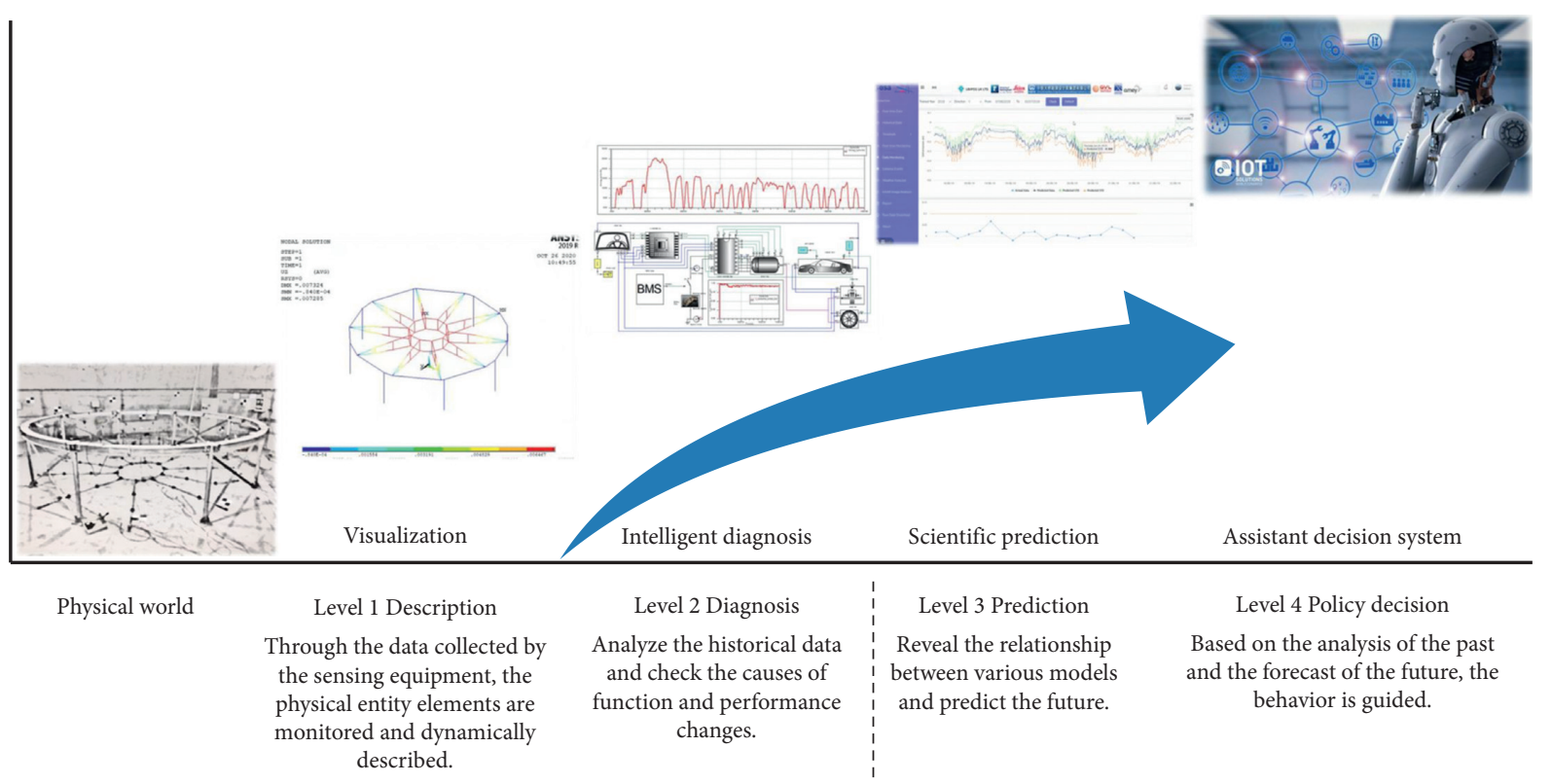

FIGURE 1: Hierarchical structure of digital twin in the structure operation and maintenance stage.

can be used as a prediction tool. After pairing with the physical spatial dimension, the monitoring system layer and data analysis layer start to operate, while maintaining a close one-to-one mapping from the physical model to the digital model, so as to find and solve problems in time before they occur.

During the operation and maintenance of the prestressed steel structure, if the components undergo brittle fatigue failure, it may cause greater casualties and property losses, and the maintenance works may take several months. In order to study the safety prediction and risk control of the operation and maintenance process of prestressed steel structure, the basic assumption of this paper is as follows: the safety risk factors of prestressed steel structure only consider the interaction between the internal components in the whole process of operation and maintenance, focus on the safety risk factors from the perspective of structural safety, and simplify the influence of external auxiliary factors on the system into a constant. Referring to the technical standards and specifications in the industry, the common and basic characteristics of security risk in the operation and maintenance stage are extracted through data analysis, and the units with safety risk factors are comprehensively defined and classified, such as the location and type of components. From the aspects of monitoring data, finite element simulation analysis, and in-depth study of component stress and node displacement, the main factors causing safety risk are found out, and then the key risk factors are analyzed to determine the characteristics and severity level of risk factors, and the evaluation index system of safety risk factors in the operation and maintenance stage of prestressed steel structure is extracted.

In view of the above security problems, the traditional maintenance strategy combining routine inspection and preventive maintenance needs to be upgraded. Therefore, this paper establishes a structural health prediction system based on advanced digital twin driving. The model consists of three main parts: real physical spatial dimension modeling, digital virtual spatial dimension modeling, and synchronous data-driven dimension modeling. The concept and definition are shown in Figure 2. In the physical space dimension, the whole monitoring period of structure operation and maintenance is taken as the time main line, and displacement, stress, strain, and other parameters are taken as important extraction features to interact with virtual space dimension and service system dimension in real time. In the dimension of virtual space, it integrates the initial digital model of BIM model, mechanical model, and operation and maintenance simulation model in the process of structural operation and maintenance, which provides high fidelity mapping for the real physical space dimension. In the datadriven dimension, twin data are the collection of data in all dimensions, providing real-time visualization, security risk prediction, and control. Through socket, RPC, and other data interfaces, sensor, embedded system, and data acquisition card are used to realize bidirectional data transmission and synchronization between physical space and virtual space, and iterative simulation, dynamic response, and prediction can be carried out based on neural network algorithm; at the same time, the original data and real-time collected data are processed and optimized to complete the monitoring of the operation and maintenance stage. The establishment of monitoring and early warning system provides technical support for the later research on security risk coupling mechanism.

2.2. Coding System. In the framework of steel structure operation and maintenance risk prediction, it is necessary to establish DTM corresponding to the physical model entity and component entity. At the same time, DTM needs to describe and correspond to the relevant information of 


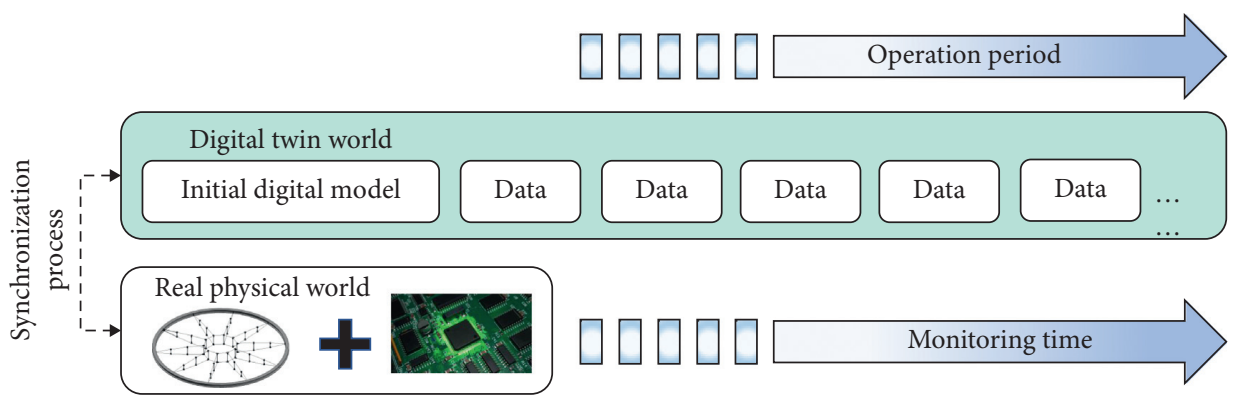

FIgURE 2: The realization of digital twin.

safety risk prediction in the process of structural operation and maintenance and then analyze the causes of safety risk in the process of operation and maintenance. This paper proposes a systematic database in which the target model is defined element by element according to the concept of a creative object-based program. The target information model is generated by assembling the entire structure using the ID of each element and its coordinates and constraint information. By adding the corresponding information requirements to the specified object ID in the inventory system, a 3D digital model based on BIM is formed. It includes all information related to the name, number, physical properties, and coordinates of each component. With the advantage of parametric modeling technology, the input information will be saved, updated, and stored in the whole life cycle of structural health.

The ID number of each member in the theoretical cable truss BIM model and the theoretical FEA model and the three-dimensional coordinates $x, y, z$ in space correspond to the cable truss structure test model one to one. The four dimensions of the cable truss component number and threedimensional coordinates are expressed in geometric form as follows:

$$
\begin{aligned}
\mathrm{ID} & =\left\{\mathrm{id}_{1}, \mathrm{id}_{2}, \mathrm{id}_{3}, \ldots, \mathrm{id}_{n}\right\}, \\
X & =\left\{x_{1}, x_{2}, x_{3}, \ldots, x_{n}\right\}, \\
Y & =\left\{y_{1}, y_{2}, y_{3}, \ldots, y_{n}\right\}, \\
Z & =\left\{z_{1}, z_{2}, z_{3}, \ldots, z_{n}\right\},
\end{aligned}
$$

where $\mathrm{id}_{1}, \mathrm{id}_{2}, \mathrm{id}_{3}, \ldots, \mathrm{id}_{n}$ are the ID numbers of each member of the cable truss. $x_{1}, x_{2}, x_{3}, \ldots, x_{n}$ represent the $x$ direction coordinates of each node, $y_{1}, y_{2}, y_{3}, \ldots, y_{n}$ represent the $y$-direction coordinates of each node, $z_{1}, z_{2}, z_{3}, \ldots, z_{n}$ represent the $z$-coordinate of each node, and the meaning of each parameter is the same in the following analysis.

The geometric expression of the theoretical BIM model is $B=\left\{\operatorname{ID}_{B}, X_{B}, Y_{B}, Z_{B}\right\}$, and the specific matrix form is as follows:

$$
B=\left|\begin{array}{c}
\mathrm{ID}_{B} \\
X_{B} \\
Y_{B} \\
Z_{B}
\end{array}\right|=\left|\begin{array}{c}
\mathrm{id}_{b 1}, \mathrm{id}_{b 2}, \mathrm{id}_{b 3}, \ldots, \mathrm{id}_{b n} \\
x_{b 1}, x_{b 2}, x_{b 3}, \ldots, x_{b n} \\
y_{b 1}, y_{b 2}, y_{b 3}, \ldots, y_{b n} \\
z_{b 1}, z_{b 2}, z_{b 3}, \ldots, z_{b n}
\end{array}\right| .
$$

The geometric expression of the theoretical FEA model is $F=\left\{\operatorname{ID}_{F}, X_{F}, Y_{F}, Z_{F}\right\}$, and the specific matrix form is as follows:

$$
F=\left|\begin{array}{c}
\mathrm{ID}_{F} \\
X_{F} \\
Y_{F} \\
Z_{F}
\end{array}\right|=\left|\begin{array}{c}
\mathrm{id}_{f 1}, \mathrm{id}_{f 2}, \mathrm{id}_{f 3}, \ldots, \mathrm{id}_{f n} \\
x_{f 1}, x_{f 2}, x_{f 3}, \ldots, x_{f n} \\
y_{f 1}, y_{f 2}, y_{f 3}, \ldots, y_{f n} \\
z_{f 1}, z_{f 2}, z_{f 3}, \ldots, z_{f n}
\end{array}\right| .
$$

The geometric expression of the cable truss structure test model is $R=\left\{\mathrm{ID}_{R}, X_{R}, Y_{R}, Z_{R}\right\}$, and the specific matrix form is as follows:

$$
R=\left|\begin{array}{c}
\mathrm{ID}_{R} \\
X_{R} \\
Y_{R} \\
Z_{R}
\end{array}\right|=\left|\begin{array}{c}
\mathrm{id}_{r 1}, \mathrm{id}_{r 2}, \mathrm{id}_{r 3}, \ldots, \mathrm{id}_{r n} \\
x_{r 1}, x_{r 2}, x_{r 3}, \ldots, x_{r n} \\
y_{r 1}, y_{r 2}, y_{r 3}, \ldots, y_{r n} \\
z_{r 1}, z_{r 2}, z_{r 3}, \ldots, z_{r n}
\end{array}\right| .
$$

In the field model test, due to processing error, installation error, and other factors, there are some differences between the theoretical BIM model, theoretical FEA model, and cable truss structure test model. BIM and 3D laser scanning technology are introduced to modify the model. Three-dimensional laser scanning technology is also known as "real scene replication" technology. Therefore, the measured model obtained by three-dimensional scanning has a time dimension. Similarly, the measured model of threedimensional laser scanning is expressed in matrix form as follows:

$$
S=\left|\begin{array}{c}
\mathrm{ID}_{S} \\
X_{S} \\
Y_{S} \\
Z_{S} \\
T_{s}
\end{array}\right|=\left|\begin{array}{c}
\mathrm{id}_{s 1}, \mathrm{id}_{s 2}, \mathrm{id}_{s 3}, \ldots, \mathrm{id}_{s n} \\
x_{s 1}, x_{s 2}, x_{s 3}, \ldots, x_{s n} \\
y_{s 1}, y_{s 2}, y_{s 3}, \ldots, y_{s n} \\
z_{s 1}, z_{s 2}, z_{s 3}, \ldots, z_{s n} \\
t_{s 1}, t_{s 2}, t_{s 3}, \ldots, t_{s n}
\end{array}\right|,
$$

where $T$ is the scanning time, which can be used to reflect the state of the structure during normal use. Other symbols have the same meaning as above. In this case, $B, F, R$, and $S$ are called the multivariate and multidimensional matrix expression of the test model of spoke cable truss. After 3D laser scanning, the structural entity test model $R$ is converted into a $3 \mathrm{D}$ laser scanning measured model $S$. Then, using the $3 \mathrm{D}$ laser scanning measured model as a correction factor, the 
theoretical BIM model $B$ is added to the time dimension, as shown in the following formula:

$$
B^{\prime}=B \bullet S=\left|\begin{array}{c}
\mathrm{ID}_{B^{\prime}} \\
X_{B^{\prime}} \\
Y_{B^{\prime}} \\
Z_{B^{\prime}} \\
T_{B^{\prime}}
\end{array}\right|=\left|\begin{array}{c}
\mathrm{id}_{b^{\prime} 1}, \mathrm{id}_{b^{\prime} 2}, \mathrm{id}_{b^{\prime} 3}, \ldots, \mathrm{id}_{b^{\prime} i} \\
x_{b^{\prime} 1}, x_{b^{\prime} 2}, x_{b^{\prime} 3}, \ldots, x_{b^{\prime} n} \\
y_{b^{\prime} 1}, y_{b^{\prime} 2}, y_{b^{\prime} 3}, \ldots, y_{b^{\prime} n} \\
z_{b^{\prime} 1}, z_{b^{\prime} 2}, z_{b^{\prime} 3}, \ldots, z_{b^{\prime} n} \\
t_{b^{\prime} 1}, t_{b^{\prime} 2}, t_{b^{\prime} 3}, \ldots, t_{b^{\prime} n}
\end{array}\right|,
$$

where $B$ is the modified BIM model and $B^{\prime}$ is the fivedimensional BIM model with time dimension added. On the basis of the five-dimensional model and the modified BIM model, two important factors of operation and maintenance safety intelligent prediction are added, which include seven dimensions: component ID number, $X$-coordinate, $Y$ coordinate, $Z$-coordinate, monitoring time $T$, early warning degree (alert), and remaining useful life $(R)$. The revised seven-dimensional FEA model is as follows:

$$
F^{\prime}=\left|\begin{array}{c}
\mathrm{ID}_{F^{\prime}} \\
X_{F^{\prime}} \\
Y_{F^{\prime}} \\
Z_{F^{\prime}} \\
T_{F^{\prime}} \\
A_{F^{\prime}} \\
R_{F^{\prime}}
\end{array}\right|=\left|\begin{array}{c}
\mathrm{id}_{f^{\prime} 1}, \mathrm{id}_{f^{\prime} 2}, \mathrm{id}_{f^{\prime} 3}, \ldots, \mathrm{id}_{f^{\prime} n} \\
x_{f^{\prime} 1}, x_{f^{\prime} 2}, x_{f^{\prime} 3}, \ldots, x_{f^{\prime} n} \\
y_{f^{\prime} 1}, y_{f^{\prime} 2}, y_{f^{\prime} 3}, \ldots, y_{f^{\prime} n} \\
z_{f^{\prime} 1}, z_{f^{\prime} 2}, z_{f^{\prime} 3}, \ldots, z_{f^{\prime} n} \\
t_{f^{\prime} 1}, t_{f^{\prime} 2}, t_{f^{\prime} 3}, \ldots, t_{f^{\prime} n} \\
a_{f^{\prime} 1}, a_{f^{\prime} 2}, a_{f^{\prime} 3}, \ldots, a_{f^{\prime} n} \\
r_{f^{\prime} 1}, r_{f^{\prime} 2}, r_{f^{\prime} 3}, \ldots, r_{f^{\prime} n}
\end{array}\right| .
$$

In this correction method, the theoretical BIM model of spoke cable truss $(B)$, the theoretical FEA model $(F)$, the test model $(R)$, and the measured model of 3D laser scan $(S)$ are used as the basis, and the seven dimensions of member number (ID number) and 3D coordinates of the cable truss as well as time, warning degree, and remaining useful life are involved in the process so that the simulation results of the final modified FEA model are closer to the test values. The final results of the modified FEA model are closer to the experimental values and ensure the accuracy of the FEA.

According to the above discussion, the application idea of multidimensional test correction method based on BIM and 3D laser scanning technology is as follows: a theoretical BIM model is established at the time of component design as equation (2), and the components are drawn and processed according to this model, and the coordinates of key points are extracted from the BIM model to establish a theoretical FEA model with the mathematical expression as equation (3). Based on the analysis results, the spoke truss is tensioned and shaped into a test model of the spoke truss structure, and its mathematical expression is shown in equation (4). In order to consider the influence of time on the spatial coordinates of the structure, 3D laser scanning technology is introduced at this time. After obtaining the point cloud data, due to the error of the machine itself and the influence of human factors and the external environment, there are a lot of outliers in the point cloud data, so it is necessary to further denoise the point cloud data, and the denoised and spliced point cloud data are imported into the BIM software to extract the key points of the cable truss structure and correct the coordinates of the theoretical BIM model to obtain the modified BIM model, whose mathematical expression is shown in equation (6). The coordinates of key nodes are extracted from the modified BIM model, and the theoretical FEA model is modified to obtain the modified FEA model considering time, warning level, and remaining service life dimensions, and that is (7), to ensure the accuracy of the simulation analysis. The coded database is always used throughout the creation of the digital twin model.

2.3. Intelligent Algorithm. From the analysis above, the cable is disturbed by many factors during operation and maintenance. The joint error and the cable length change caused by tensile tension are the factors which must be considered. Therefore, in the digital twin-driven structure health prediction framework, the internal force and deflection in the operation and maintenance process of cable components are predicted by intelligent algorithm, and the prediction results are fed back to the control system, which is very necessary to realize the real-time, dynamic, and accurate control of each cable network node.

For the nonlinear process of cable net structure loading, traditional mathematical model methods are difficult to achieve ideal prediction results. Artificial neural network (artificial neural network), as a commonly used mathematical modeling method nowadays, is self-contained for large samples. For the nonlinear process of cable net structure loading, the traditional mathematical model methods are difficult to achieve the ideal prediction effect. As a common mathematical modeling method, artificial neural network (ANN) has adaptive ability to large samples. Through the learning of historical data, the mapping relationship between input and output can be found, and this mapping relationship can be extracted and stored during the learning process. In the prediction stage, the following information can be obtained according to the input of the network. In the prediction stage, according to the input of the network, we can get the prediction output of the next period. In dealing with these uncertain problems, we can reduce the error of state evaluation through a large number of sample learning, so as to get the correct results. At the same time, neural network has the ability to store and sort data and good generalization ability. Therefore, ANN can be used as an important technical means in the digital twin prediction system in the production environment where a large amount of data has been collected.

ANN is modeled based on the biological nervous system, which is mainly used for machine learning to solve mathematical problems. The neural network has two steps: feedforward step and backpropagation step. Firstly, in the feedforward step, the hidden layer neurons take the value of each connected input neuron and multiply it with its connection weight. The weights of all connected input neurons and the deviation value of neurons are put into the so-called activation function (transfer function), which mathematically converts the value into a probability value (between 0 and 1) and finally transfers it to the output layer. 
Repeat the same process again between the hidden layer and the output layer to calculate the output prediction. The input is then propagated across the network. The logic sigmoid activation function is shown in formulas (8) and (9) because the logic sigmoid activation function is used in both the hidden layer and the output layer because it can lead to a well-trained process. The structure and mathematical representation of the artificial neuron are shown in Figure 3, and its mathematical model is as follows:

$$
\begin{aligned}
f(\text { sum }) & =\frac{1}{1+e^{- \text {sum }},} \\
\text { sum } & =\sum_{i=1}^{n} X_{i} W_{i}+B,
\end{aligned}
$$

where $f($ sum) is the activation function; sum is the weighted sum, $X_{i}$ is the input of neuron $i, W_{i}$ is the connection weight between two neurons, and $B$ is the deviation value. Secondly, backpropagation (BP) step is one of the many algorithms used to train ANN. The algorithm continuously propagates the error backward and adjusts each network weight and deviation value (output and hidden layers) to the direction of minimizing network output error. Thus, the prediction output is closer to the target output, and the whole network error is reduced to a satisfactory level. Many techniques can be used in backpropagation algorithms, such as gradient descent method, quasi-Newton method, and Levenberg-Marquardt (LM) method.

This article mainly solves the problems that may occur in the operation and maintenance stage of the two types of prestressed steel structures. The main control parameters are introduced, respectively. The first type of problem is the increase in the internal force of some members caused by the loss of prestress, so the input vectors are different at this time. The percentage of residual prestress of the component (\%); the output vector is the rate of change of the cable force of different components (\%) and the node displacement $(\mathrm{mm})$. The second type of problem is the change of the internal force of the member caused by the uneven force of the overall structure under the action of rain and snow, so the input vector is the force loaded by different nodes $(\mathrm{kN})$; the output vector is the cable force value of different members $(\mathrm{kN})$ and the deflection value $(\mathrm{mm})$.

2.4. Digital Twin Model Establishment. The establishment of the digital twin model in accordance with the actual structure of prestressed steel structure is the core of establishing the prediction and health management system in the prototype of the above guidance method. Based on the above multisource information, the virtual and real mapping modeling of physical space and virtual space is carried out, and the digital twin model of security risk in the cable operation and maintenance stage (including real physical space dimension, digital virtual space dimension, and data verification service) is established. The specific six-dimensional model of digital twin is shown in Figure 4.

The relationship of each part can be summarized as $\mathrm{DTM}=(\mathrm{SE}, \mathrm{SEE}, \mathrm{DP}, \mathrm{PCM}, \mathrm{SA}, \mathrm{EWS})$, where DTM is the structural operation and maintenance security model driven by digital twin, SE is the physical entity of the building, SEE is the physical entity of the sensor, DP is the data preprocessing module, $\mathrm{PCM}$ is the $3 \mathrm{D}$ point cloud model, $\mathrm{SA}$ is the real-time simulation analysis, and EWS is the early warning system.

In the digital twin-driven structural O\&M safety model established with a spoke cable truss as an example, the SE module is the test model $R$ in the coding system in Section 2.2 above, the PCM module contains the theoretical BIM model $B$ and the measured model $S$ from 3D laser scanning, and the SA module is the theoretical finite element analysis model $F$. The SA module transmits the predicted data to the EWS module through the neural network intelligent algorithm and records the seven dimensions of component ID, $3 \mathrm{D}$ coordinates, time, warning level, and remaining service life in the coding system as described above.

It can be seen that the digital twin-driven equipment fault prediction and O\&M management service model brings the following new changes to the traditional O\&M approach: (1) the change of fault detection mode replaces the traditional static lagging indicator with real-time interaction and multidimensional state comparison of dynamic physical and virtual digital; (2) the change of the fault analysis mode from the analysis mode based on the operating characteristics of the physical equipment of the building based on experience to the analysis mode combining the digital characteristics of the operation of the physical and virtual digital equipment; and (3) the implementation mode of the equipment fault prediction and health management function from passive distribution to active and precise service.

\section{Case Study}

3.1. Realistic Physical Space Modeling. The dimension of real physical space includes structure entity (SE), sensor entity (SEE), and data preprocessing module (DP). First of all, the data are recorded by sensors from the structural entities in the physical space dimension, including the basic attributes of the parameters in the operation and maintenance stage, such as temperature, humidity, load history, and monitoring data, and the data preprocessing (monitoring and operation and maintenance) is carried out according to the feedback control and scheduling command. The recorded data (realtime data and historical data) are used to study the fusion of mechanical model, simulation model, and monitoring data and safety management information in the process of structural operation and maintenance.

Determine the scope of the model test according to the actual engineering model. This model test adopts the size that is completely scaled to the engineering for the test. The principle of determining the cross section of the outer ring steel structure is to make the overall rigidity similar to that of the outer ring structure of the original project, and the stress ratio of all the members is the same. The model specimen is scaled to $1: 10$ according to the assumed diameter of $60 \mathrm{~m}$ structure. The test model is a spoke-type cable truss structure with a diameter of $6 \mathrm{~m}$, consisting of 10 radial cables and two 


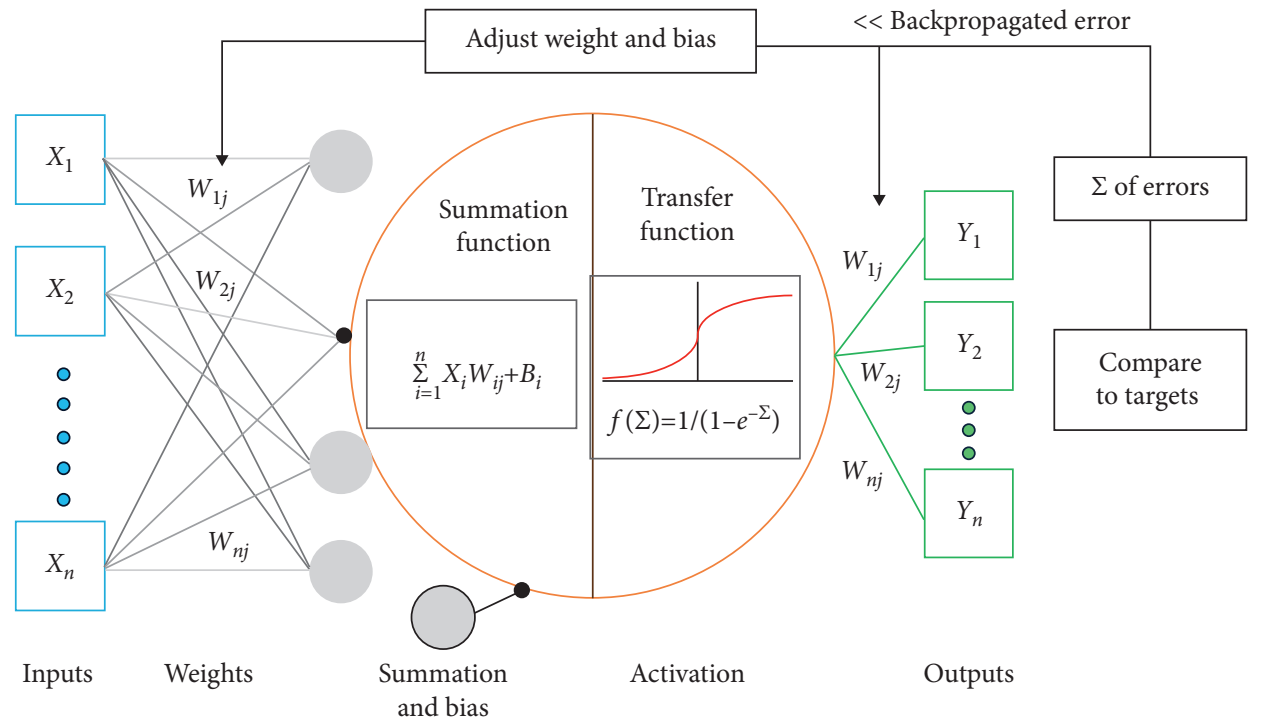

FIgURE 3: Structure of a single BP artificial neuron (hidden neuron) and mathematical representation.

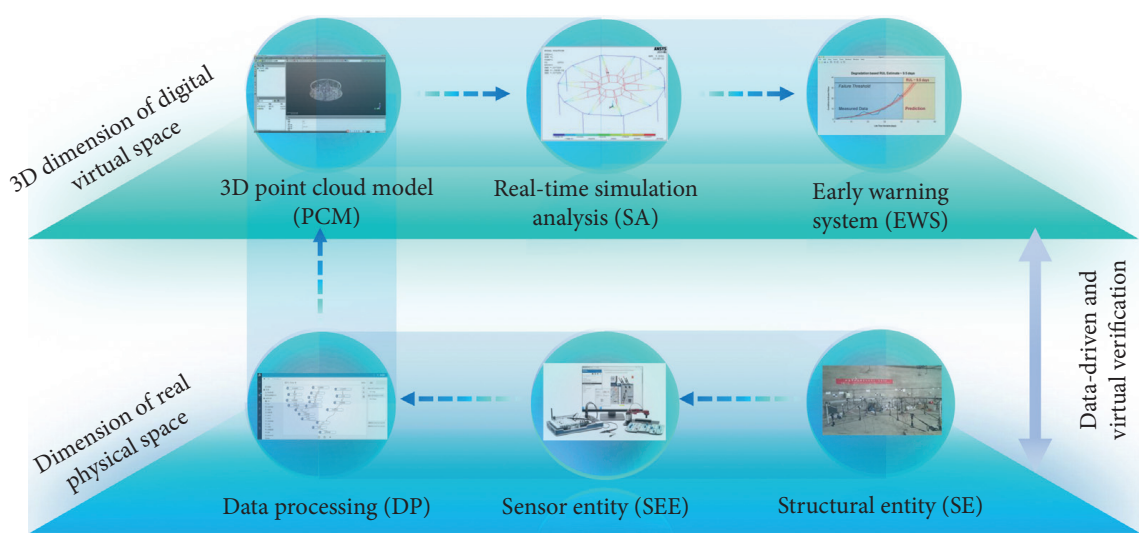

FIGURE 4: Structural health prediction system framework driven by digital twins.

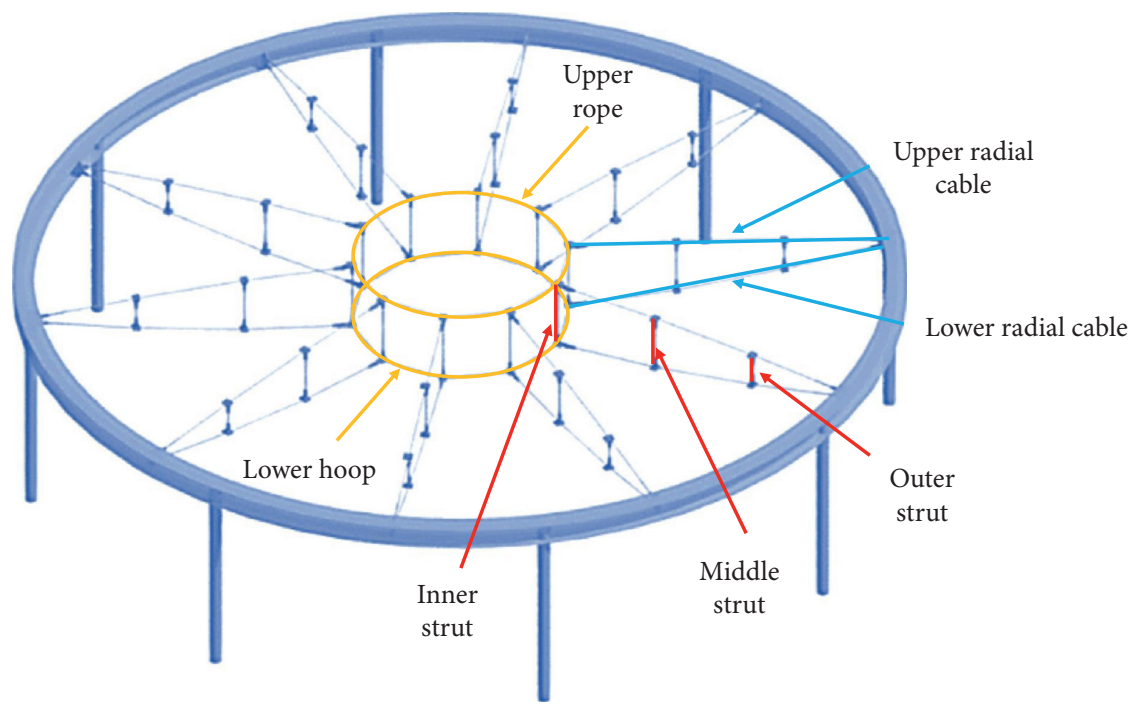

Figure 5: 3D model. 
TABle 1: Model material specification selection.

\begin{tabular}{lccc}
\hline Lever & Position & Model specifications & Model cross-sectional area $\left(\mathrm{mm}^{2}\right)$ \\
\hline \multirow{2}{*}{ Radial cable } & Up & $6^{*} 7 \Phi 8$ & 24.6 \\
Girdle & Down & $6^{*} 19 \Phi 10$ & 33.3 \\
& Upper circle & $6^{*} 7 \Phi 8$ & 24.6 \\
Brace & Lower circle & $6^{*} 19 \Phi 12$ & 49.1 \\
& Outer circle & $\Phi 12^{*} 2$ & 62.8 \\
Ring beam & Middle circle & $\Phi 12^{*} 2$ & 62.8 \\
\hline
\end{tabular}

loop cables. The three-dimensional and flat elevations of the model are shown in Figure 5.

Based on the calculation and analysis of the structural model, the structural design drawings, and the market supply, the materials and specifications selected for the model are shown in Table 1. According to the calculation and analysis, various members of the structural model test are selected, among which the cable level is 1570 .

According to "General Technical Requirements for Wire Rope" (GB/T 20118-2017), the minimum breaking force of upper radial cable and upper ring cable is $33.4 \mathrm{kN}$, and that of lower radial cable and lower ring cable is $51.8 \mathrm{kN}$ and $74.6 \mathrm{kN}$, respectively. The conversion relationship between allowable stress and minimum breaking stress is shown in the following formula. Here, the conversion coefficient is 0.88 and 0.85 , respectively, and the safety factor is 4 .

$$
F_{\text {allowable }}=F_{\text {Break }} * \frac{\text { conversion factor }}{\text { safety factor }} \text {. }
$$

After calculation, $F_{\text {allowable }}$ in the upper radial cable and upper rope is $7,348 \mathrm{~N}, F_{\text {allowable }}$ in the lower radial cable is $11,000 \mathrm{~N}$, and $F_{\text {allowable }}$ in the lower hoop is $15,850 \mathrm{~N}$.

3.2. Digital Virtual Space Modeling. The dimension of digital virtual space includes three-dimensional point cloud model (PCM), real-time simulation analysis module (SA), monitoring, and early warning system (EWS). In the process of digital modeling, the most critical technology is the accurate correspondence from real physical space to digital virtual space. Therefore, high-precision sensors and measuring equipment have been installed on the key components of the cable network structure in the operation and maintenance stage. For example, magnetic flux sensors are installed in the upper and lower suspension cables and the upper and lower ring cables to measure the force of the main cable at the boundary. The reflected targets measured by laser have been distributed on the ear plate pinholes of the annular beam, to ensure that the coordinates of these pinholes can be automatically measured by laser total station. These highprecision sensors and measuring equipment can be used to construct a DT model of prestressed steel structure at low cost. However, considering some uncontrollable factors such as machining error and installation error, there will be some deviation between the experimental data and the theoretical FEA data. After the tension of the spoke cable truss is completed, the solid test model is obtained by a 3D laser

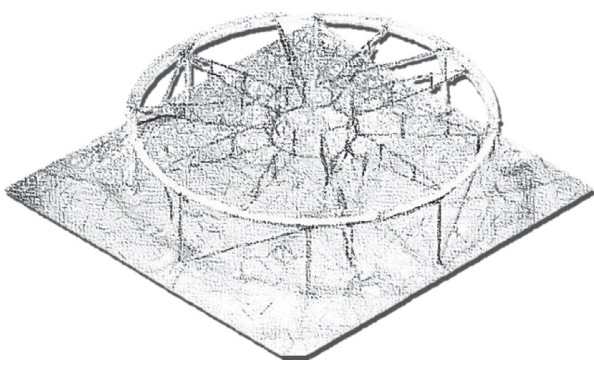

Figure 6: Point cloud model after stretching.

scanner, and the point cloud model is obtained according to the $3 \mathrm{D}$ scanning. The point cloud model is shown in Figure 6.

Based on the measured coordinates of the ear plate pinhole center and the lower tether anchorage coordinates, the DT model was modified geometrically, and the model was analyzed by the finite element method. According to the analysis results, the deviation between the calculated value and the measured value should be divided into radial deviation and tangential deviation. Considering the high precision of manufacturing and installation of cable net structure, the radial deviation of cross node is mainly related to the stiffness change caused by catenary action of lower cable. Therefore, according to formula (11), the modified value of elastic modulus caused by catenary action is calculated, and the elastic modulus of the corresponding lower cable element in the DT model is modified.

$$
\Delta E_{i}=\frac{F_{i} \times L_{i}}{\Delta L_{i} \times A_{i}}
$$

where $\Delta E_{i}$ is the modified value of elastic modulus of the $i$-th lower mooring cable, $F_{i}$ is the calculated cable force of the $i$ th lower mooring cable, $L_{i}$ is the length of the $i$-th lower mooring cable, $\Delta L_{i}$ is the radial deviation between the calculated position and the measured position of the $i$-th lower cable cross section, and $A_{i}$ is the cross-sectional area of the $i$-th lower mooring cable. The tangential deviation is mainly caused by the predetermined initial strain of the main cable in the model. According to the measured cross node coordinates and the calculated cross node coordinates, the measured length and model length of each cable under the same conditions can be obtained. Then, the correction value of the initial strain of the main cable is calculated by the formula. The following equation is used to modify the strain of the main cable in the DT model: 


$$
\Delta \epsilon_{i}=\frac{L_{i 1}-L_{i 2}}{L_{i 2}},
$$

where $\Delta \epsilon_{i}$ is the initial strain correction of the $i$-th main cable, $L_{i 1}$ is the measured length of the $i$-th main cable, and $L_{i 2}$ is the calculated length of the $i$-th main cable.

According to the above method, the relevant parameters can be updated iteratively until the deviation between the calculated position and the measured position is less than $5 \mathrm{~mm}$. At this time, $X_{F^{\prime}}, Y_{F^{\prime}}, Z_{F^{\prime}}$, and $T_{F^{\prime}}$ in the coding system are modified and recorded in the updated FEA model. The finite element program is written by the APDL language of ANSYS software to realize the automatic updating of the DT model. The update process flowchart is shown in Figure 7.

Since the cable net is fixed on the ear plate joint of the ring beam by 20 main cables, the error between measured force and calculated force of 20 main cables can best prove the accuracy of the DT model. According to "Technical Specification for Cable Structure" (JGJ257-2012), the safety factor of cables in cable net structure should be 2.5. Because of the higher refinement degree of digital twin technology, the safety factor of stay cable in cable net structure in this paper is 2.0 if designed according to allowable stress method. Considering that the measurement error of the flux sensor is $0-3 \%$, the error between the calculated value and the measured value of 20 cables is less than $13 \%$, which indicates that DT model can be successfully corrected. After updating the DT model for the first time, the accuracy of the DT model is verified by measuring the forces of 20 main cables in the basic state five times. Figure 8 shows the force error between measurement and calculation. Most of the errors between measurement and calculation are within $10 \%$, and the maximum error is only $12.41 \%$. Therefore, the accuracy of the modified DT model can meet the requirements of fault prediction and health management in cable net structure operation and maintenance system.

The key node coordinates of the corresponding theoretical model are obtained through the point cloud model. The modified finite element model is established according to the node coordinates of the point cloud model. The local error in the operation and maintenance stage is considered in the modified model. The data obtained from the analysis can better reflect the static performance of the actual test model.

Considering the powerful programming ability of ANSYS parametric design language (APDL), this paper uses APDL to construct a DT model of prestressed steel structure. Figure 9 shows the overall finite element model of prestressed steel structure, in which the strut member adopts Link8 element, the cable adopts Link10 element and applies prestress by applying initial strain method; the ring beam adopts beam 188 element, and the actual weight of reflection plate is applied to the intersection node in the form of load.

Through the digital communication between the OPC module of MATLAB and PLC, real-time feedback data can be obtained. In this way, each round of data takes less than a second. The new data acquired each time will be stored in the .txt file of the specified folder, replacing the old data file. Therefore, ANSYS can perform real-time simulation analysis by calling .txt files.

\subsection{Intelligent Prediction of Operation and Maintenance Safety of Spoke-Type Cable Truss}

3.3.1. Risk Level Assessment in Operation and Maintenance Stage. In the early warning evaluation of the indicators of this test, refer to the relevant structural specifications. According to the "Technical Regulations for Prestressed Steel Structures," the ratio of the maximum deflection to the span of the double-layer cable system should not be greater than $1 / 250$ after the initial prestress state. The maximum deflection of the cable truss is $24 \mathrm{~mm}$. In engineering practice, it is recommended that the inverted arch value in the prestressed state should not be greater than 1/400 of the span, and the recommended maximum deflection of the cable truss is $15 \mathrm{~mm}$. The bearing capacity and stiffness of cable structure nodes should be checked and calculated in accordance with the current national standard "Code for Design of Steel Structures." The cable structure node should meet the requirement that its bearing capacity design value is not less than 1.25 to 1.5 times the design value of the cable internal force. The current research is based on neural network to detect whether the location is damaged, but such a detection is a typical $0-1$ classification problem and cannot effectively identify the damage value and provide early warning. Therefore, a reasonable early warning hypothesis is proposed here, as shown in Table 2.

According to the previous definition, a complete structural health monitoring should include the following five stages: detection of damage, determination of damage location, determination of damage type, evaluation of damage degree, and structural reliability or residual life estimation. This definition can better reflect the whole life process of damage identification. When applying BP neural network to early warning evaluation of cable net structure, all data must be classified according to certain grade standards. The grading standard refers to Table 2 . In order to better describe the evaluation results, the early warning level is divided into four levels: normal, blue, orange, and red. The warning level obtained by the monitoring system will update and record $A_{F^{\prime}}$ in the coding system in real time.

3.3.2. Simulation Test Verification. In order to verify the feasibility of 3D point cloud model in the dimension of digital virtual space to real-time simulation analysis, two groups of representative tests are selected for simulation analysis: (1) 1.0 dead load +1.0 live load for full span and (2) 1.2 dead load +1.4 live load for full span. The results are shown in Figures 10-12. Through the analysis, it can be concluded that the ANSYS simulation analysis results are in good agreement with the physical test results: in Figures 11(b) and 12(b), all the components with large displacement in the physical test deflection result diagram appear in the blue and orange warning areas; under the two conditions, all the cable force values of all cable components do not reach the allowable stress, which does not constitute a warning situation. 


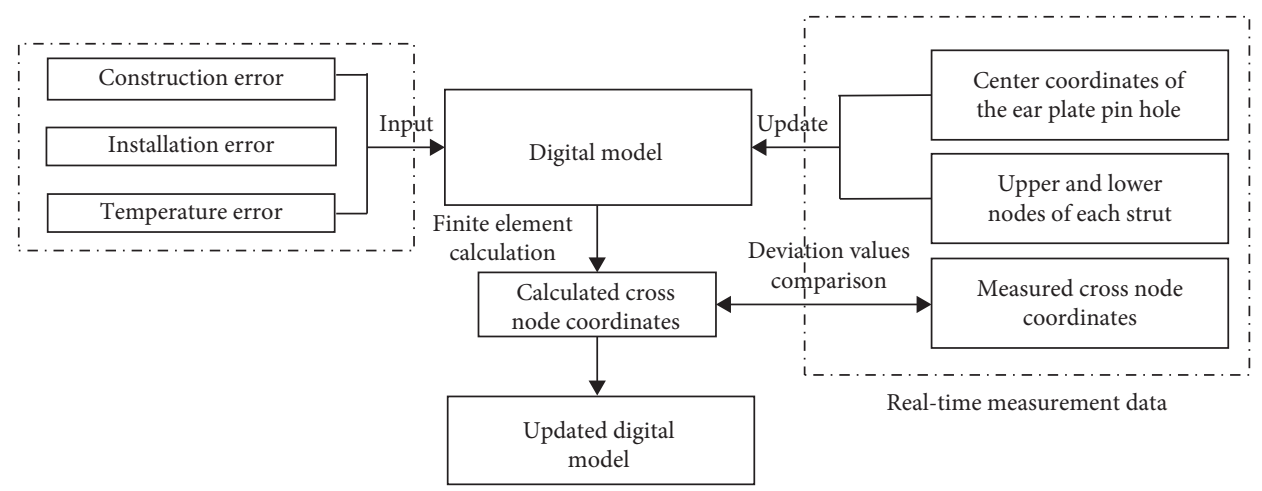

Figure 7: Update model process flowchart.

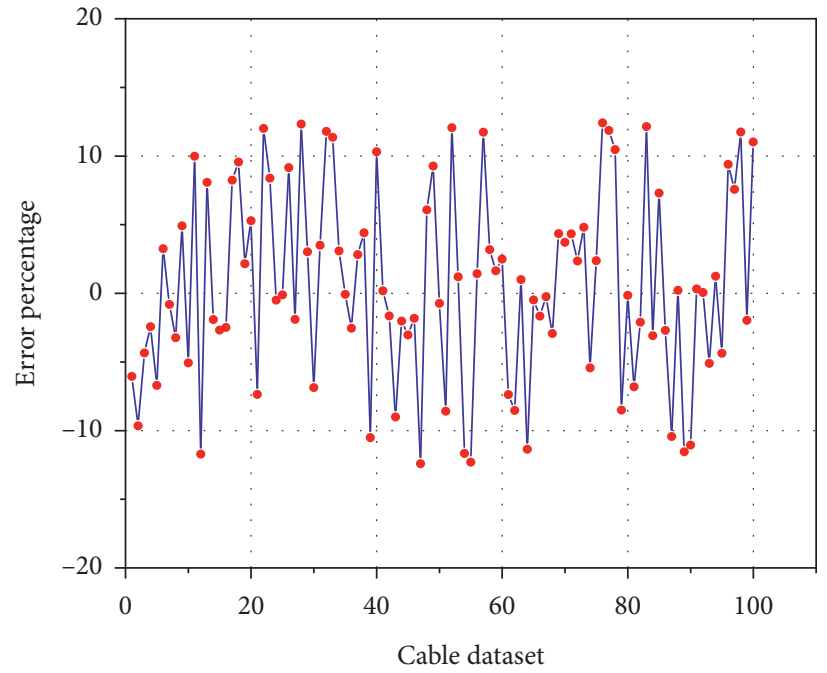

$\rightarrow$ - Cable force error

Figure 8: Cable force error between the measured value and the calculated value.

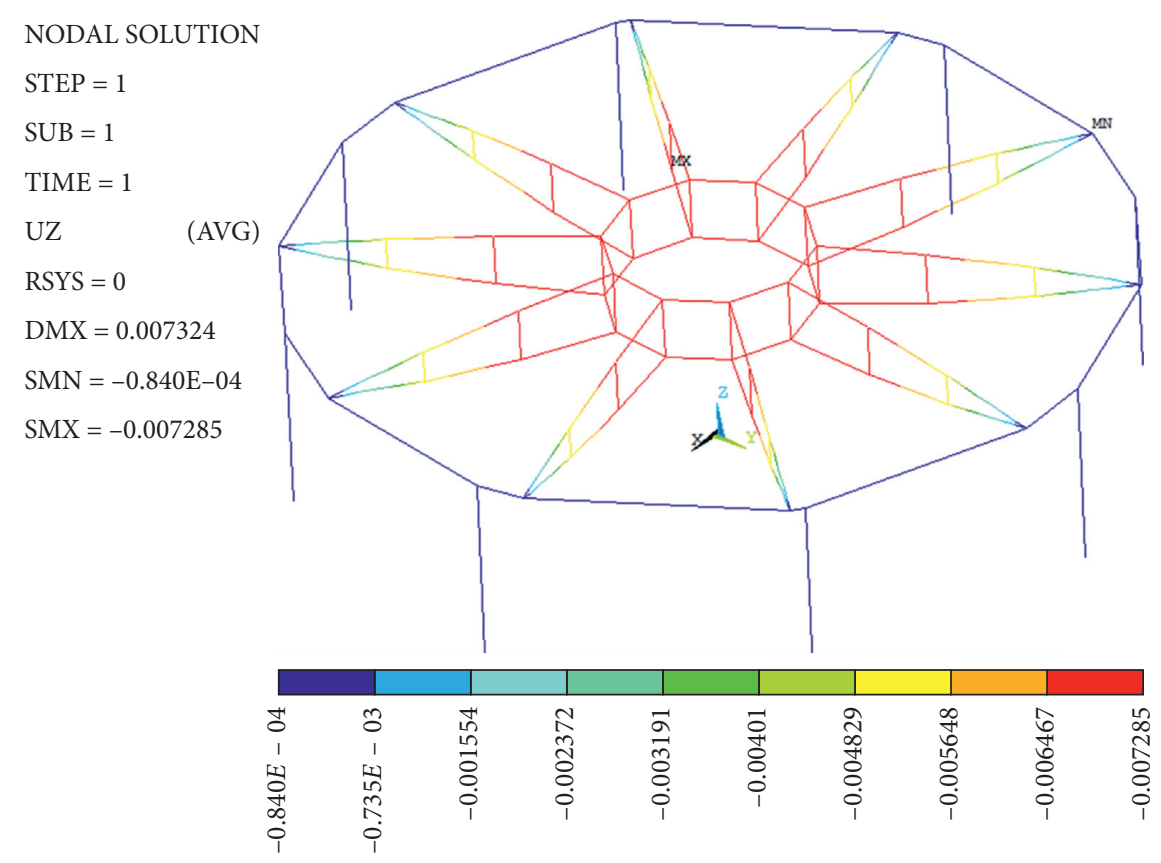

Figure 9: Finite element model of spoke-type cable truss. 
TABLE 2: Warning value of deflection and cable force.

\begin{tabular}{lcc}
\hline & Deflection $(\mathrm{mm})$ & $F_{\text {actual }} / F_{\text {allowable }}$ \\
\hline Normal value & $<15$ & $<1.3$ \\
Blue alert & 15 & 1.3 \\
Orange alert & 19 & 1.4 \\
Red alert & 24 & 1.5 \\
\hline
\end{tabular}
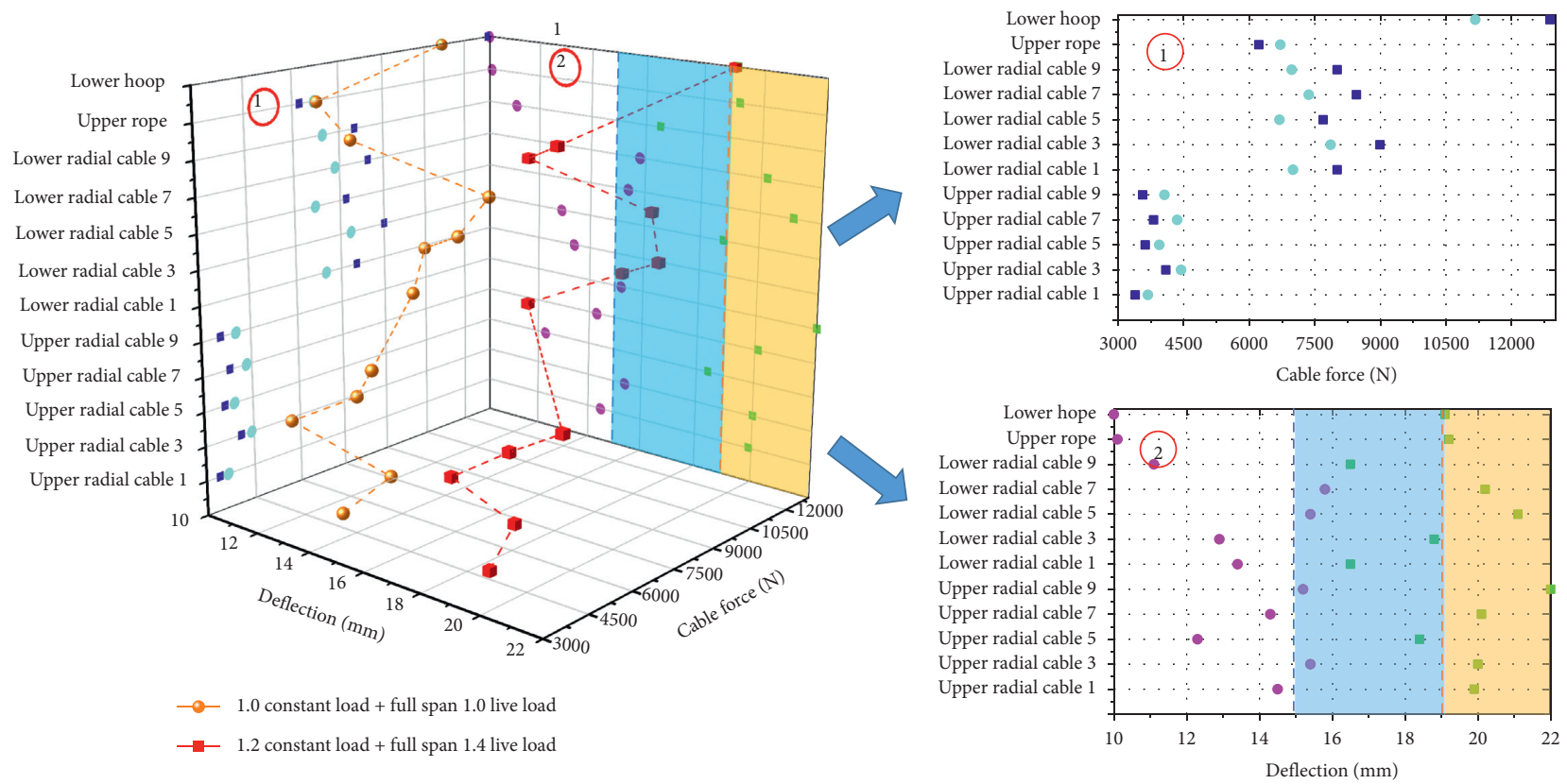

Figure 10: Physical test results under two working conditions.

NODAL SOLUTION

$\mathrm{STEP}=1$

SUB $=1$

TIME $=1$

SMIS1

(NOAVG)

$\mathrm{DMX}=0.012553$

$\mathrm{SMN}=-18254.7$

SMX $=11767.2$

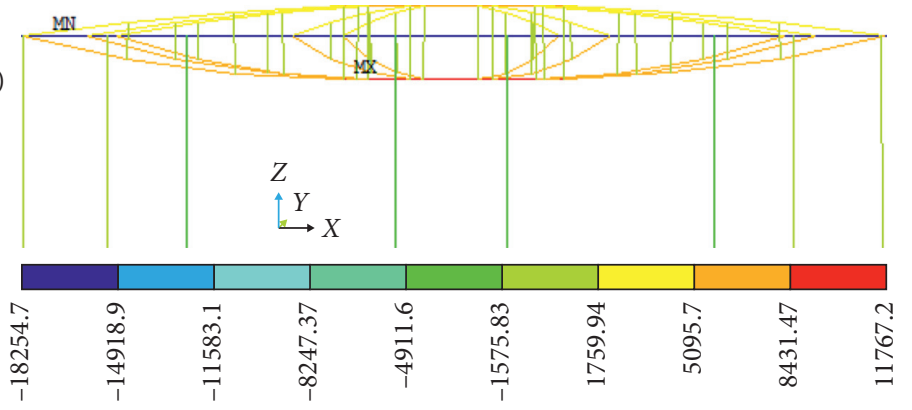

(a)

Figure 11: Continued. 


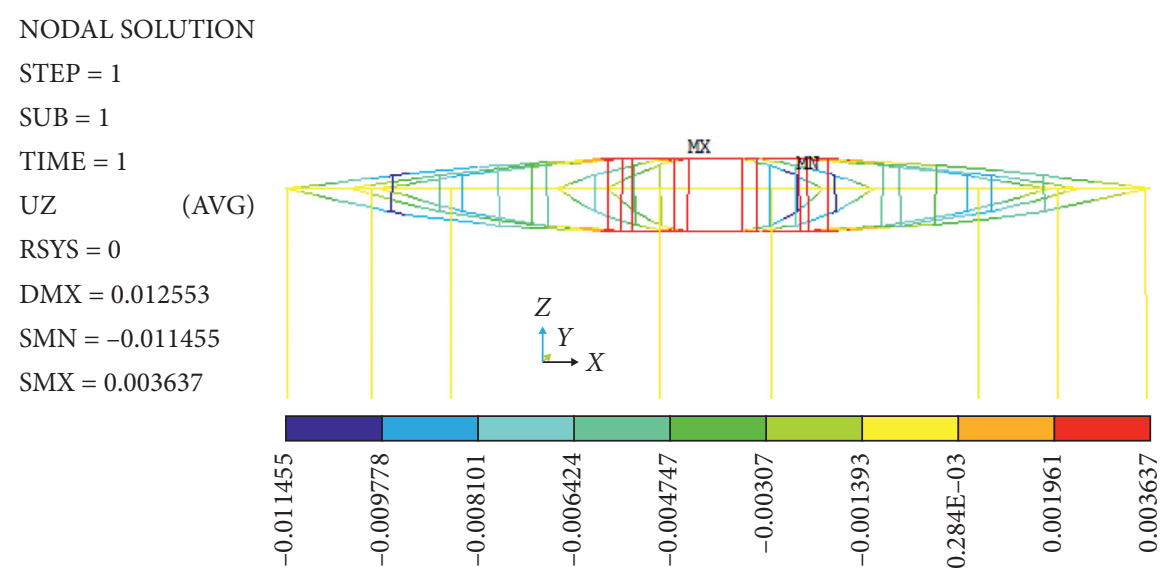

(b)

FIGURE 11: 1.0 constant load + full span 1.0 live load real-time simulation analysis diagram. (a) Model internal force diagram (N). (b) Model displacement diagram $(\mathrm{m})$.

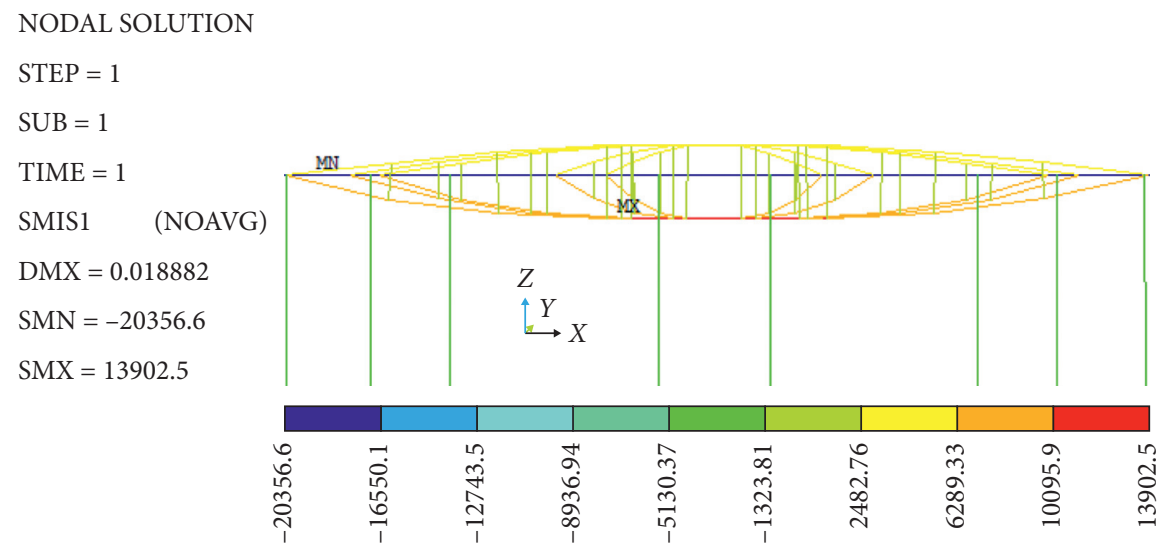

(a)
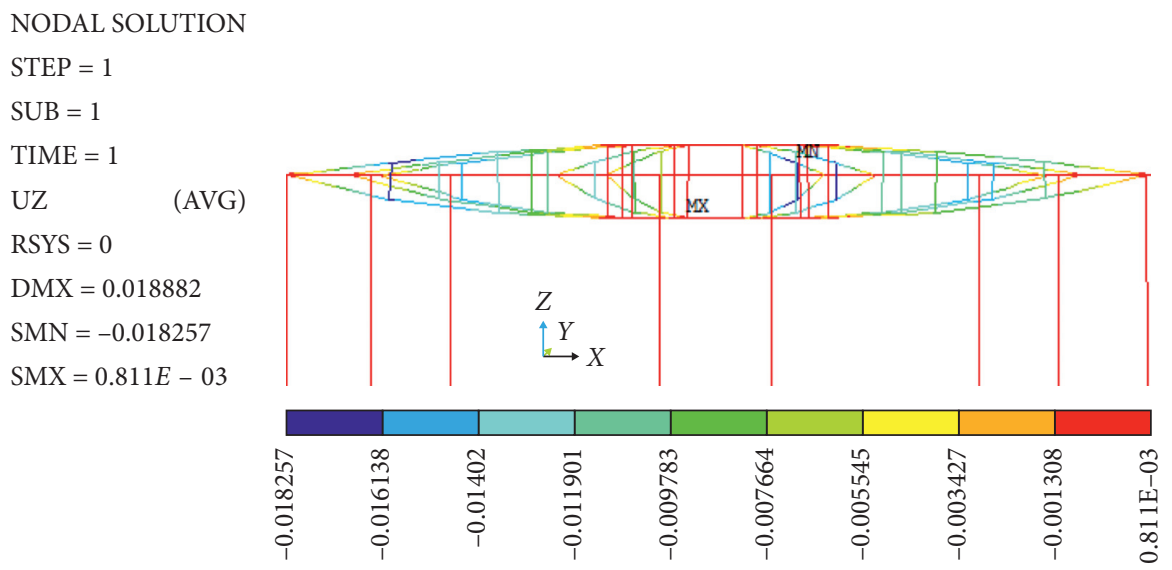

(b)

Figure 12: 1.2 constant load + full span 1.4 live load real-time simulation analysis diagram. (a) Model internal force diagram (N). (b) Model displacement diagram $(\mathrm{m})$.

Therefore, the modified model data obtained by threedimensional scanning under self-weight state are imported into the FEA, which shows that the values of cable force and displacement are in good agreement, which indicates the feasibility of PCM to SA module, and the finite element model of spoke steel frame can be used to predict the internal 
force and joint displacement of the spoke steel frame in the future analysis, which can ensure the measured position. The accuracy of moving data has good predictability.

3.3.3. Dataset Expansion. In this structure, the designed prestress value has been applied to the cable member, but in the actual project, due to the error caused by operation error and environmental factors, the cable will be relaxed to a certain extent. Prestress is a self-balancing force system in the structure system. If the prestress loss occurs, the force system will reach a new balance, thus causing the internal force changes of some components, which may have adverse effects on the overall structure. In order to further expand the dataset for machine learning in the monitoring and early warning system, the BP neural network prediction model was established to explore 47 groups of different prestress loss cases 12 input neurons: the relaxation residual prestress percentageupper radial of cables $1-5$, lower radial cables 6 10 , upper rope and lower hoop; 10 hidden neurons; 5 output neurons: the cable force change rate of the upper radial cable, lower radial cable, upper rope, lower loop and the maximum displacement of the lower node of the inner strut and 196 groups of different static load combinations (30 input neurons: different nodes loaded with different forces; 10 hidden neurons; 1 output neuron: lower ring cable force).

It can be seen from Figures 13 and 14 that the overall error between the test value based on the relaxation test of the spoke cable truss and the prediction value based on the neural network fluctuates is about $8 \%$. The results show that the neural network is successful in learning and testing. Therefore, the neural network has a high simulation and learning ability. According to the established BP model, the predicted value and relative error value of the maximum displacement under the internal strut under different working conditions are obtained, as shown in Figure 15. As can be seen from Figure 16, most of the predicted values have little difference from the measured values. The absolute value of the error is basically between 0 and $1 \mathrm{~mm}$, and only three groups of prediction errors exceed $1 \mathrm{~mm}$. The coefficient of determination $R^{2}$ is 0.98 , which indicates that the prediction effect of overall displacement is good.

In the test, it takes 0.5 hours on average for each test from changing prestress of adjusting sleeve to recording data and then to data analysis, and it takes a total of 24 hours to analyze all working conditions. The BP neural network model can predict the results with $92.1 \%$ accuracy, and the time is only a few seconds. Therefore, ANN is a powerful prediction tool and a good alternative method to solve a complex problem, such as calculating the change rate of cable force and the internal force of members after cable relaxation.

3.3.4. Early Warning System Verification. Under normal circumstances, the lower radial cable in the prestressed cable net structure is more stressed than the upper radial cable. This section will conduct multiangle monitoring in time and space for the radial cable under a certain working condition. The monitoring and early warning results are shown in

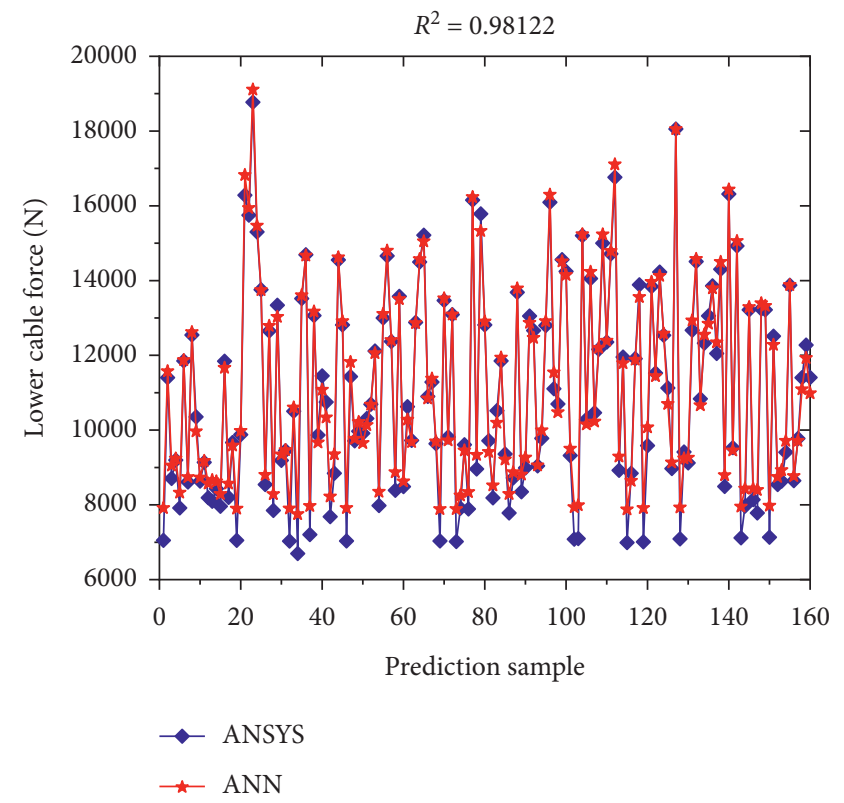

FIgURE 13: Comparison of prediction results of cable forces under suspension.

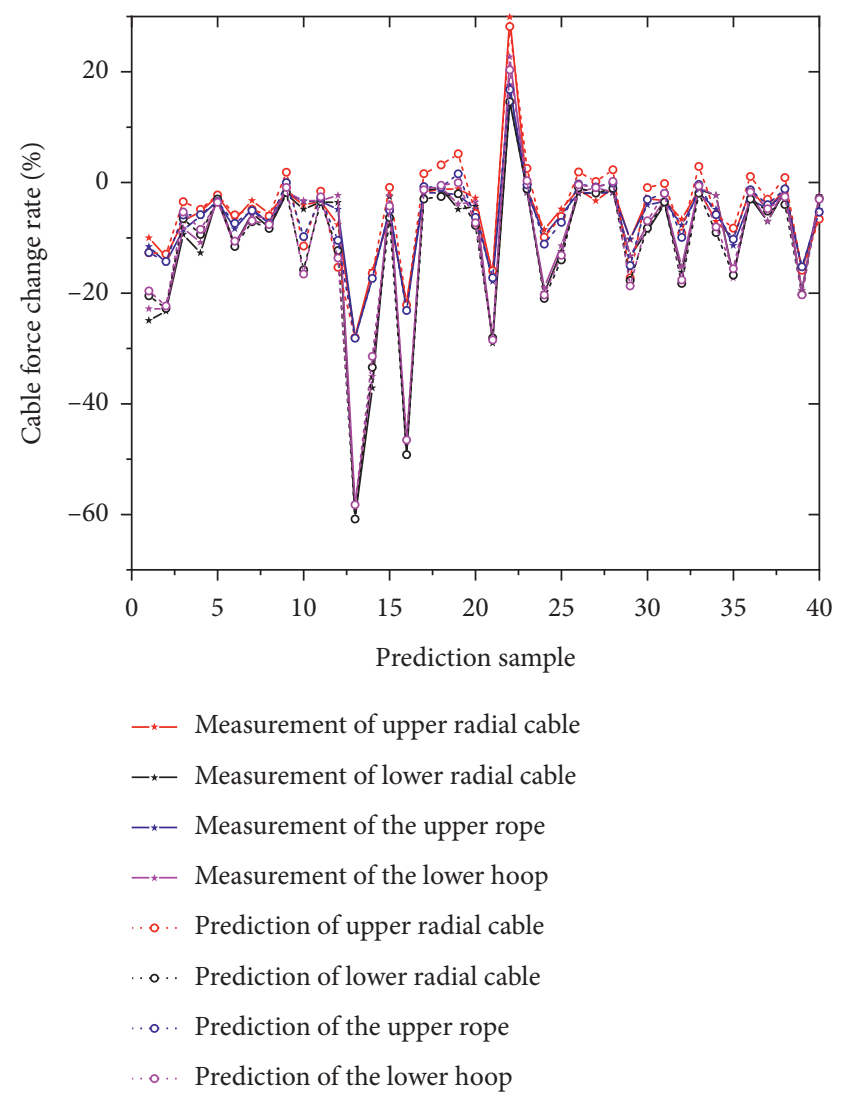

FIGURE 14: Comparison of prediction results of cable force change rate in the training set.

Figure 17. With the continuous loading of the structure, the cable force value and deflection value of the lower radial cable continue to increase. When the test was loaded for 


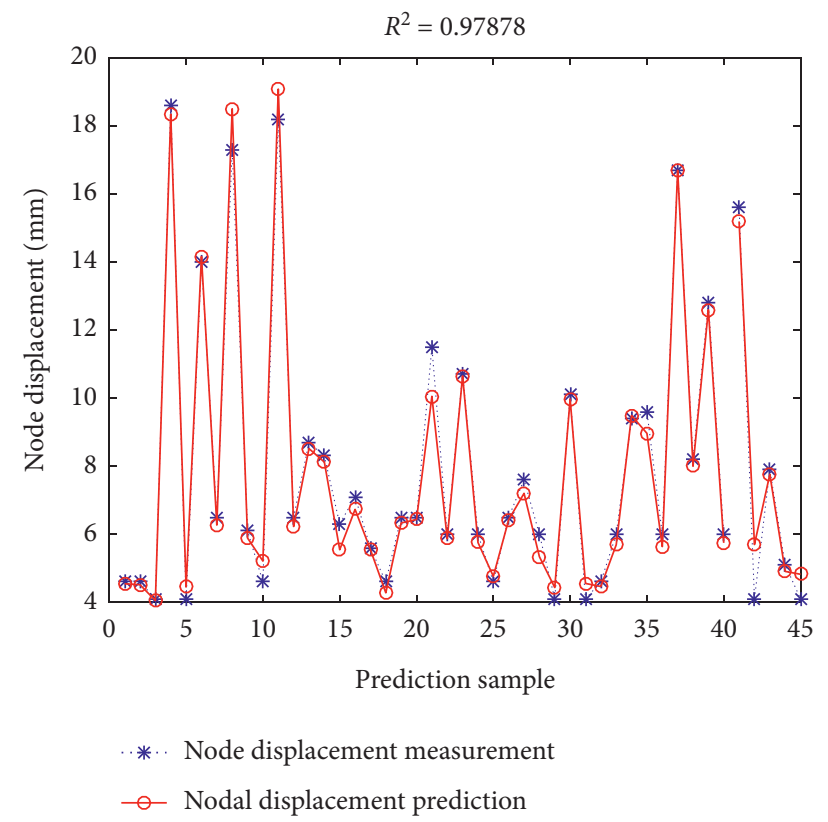

Figure 15: Comparison of prediction results of maximum displacement of nodes under the inner brace.

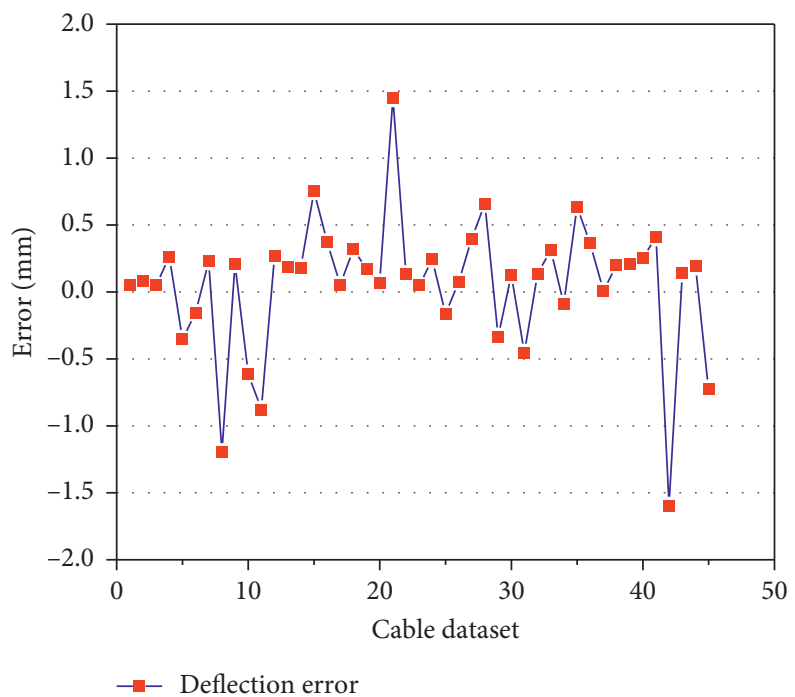

FIgURE 16: Distribution of maximum displacement error of nodes under the inner brace.

$640 \mathrm{~s}$, the measured value of the cable force reached $15,317 \mathrm{~N}$, and the system entered the blue warning state; when the test was loaded for $680 \mathrm{~s}$, the measured value of the cable force reached $16,438 \mathrm{~N}$, which was about to reach the orange warning line. In terms of deflection, when the test was loaded for $700 \mathrm{~s}$, the actual measured value of the deflection of the lower radial cable reached $15.59 \mathrm{~mm}$, entering the blue warning state. In order to prevent structural damage, this test decided to stop loading at $700 \mathrm{~s}$. However, it can be seen from the prediction curve of the early warning system that if the load continues, the cable force will reach the red warning value in 880 seconds; in terms of deflection, the deflection of the lower radial cable will reach $19 \mathrm{~mm}$ at $920 \mathrm{~s}$, entering the orange warning state. At this time, the updated FEA model will update and record $A_{F^{\prime}}$ and $R_{F^{\prime}}$ in the coding system in real time.

Through the establishment of the digital twin model for the operation and maintenance process of the steel structure case, the data in the whole operation and maintenance process can be obtained comprehensively. For the concept of digital twin, combined with intelligent algorithm, the geometric information of different components of prestressed steel structure such as size, shape, and position relationship is sorted out; through monitoring the physical information such as stress, strain, deflection, and damage in the process of test, it is proposed that the safety risk of cable operation and maintenance mainly induces components and early warning information of possible danger in the future, so as 

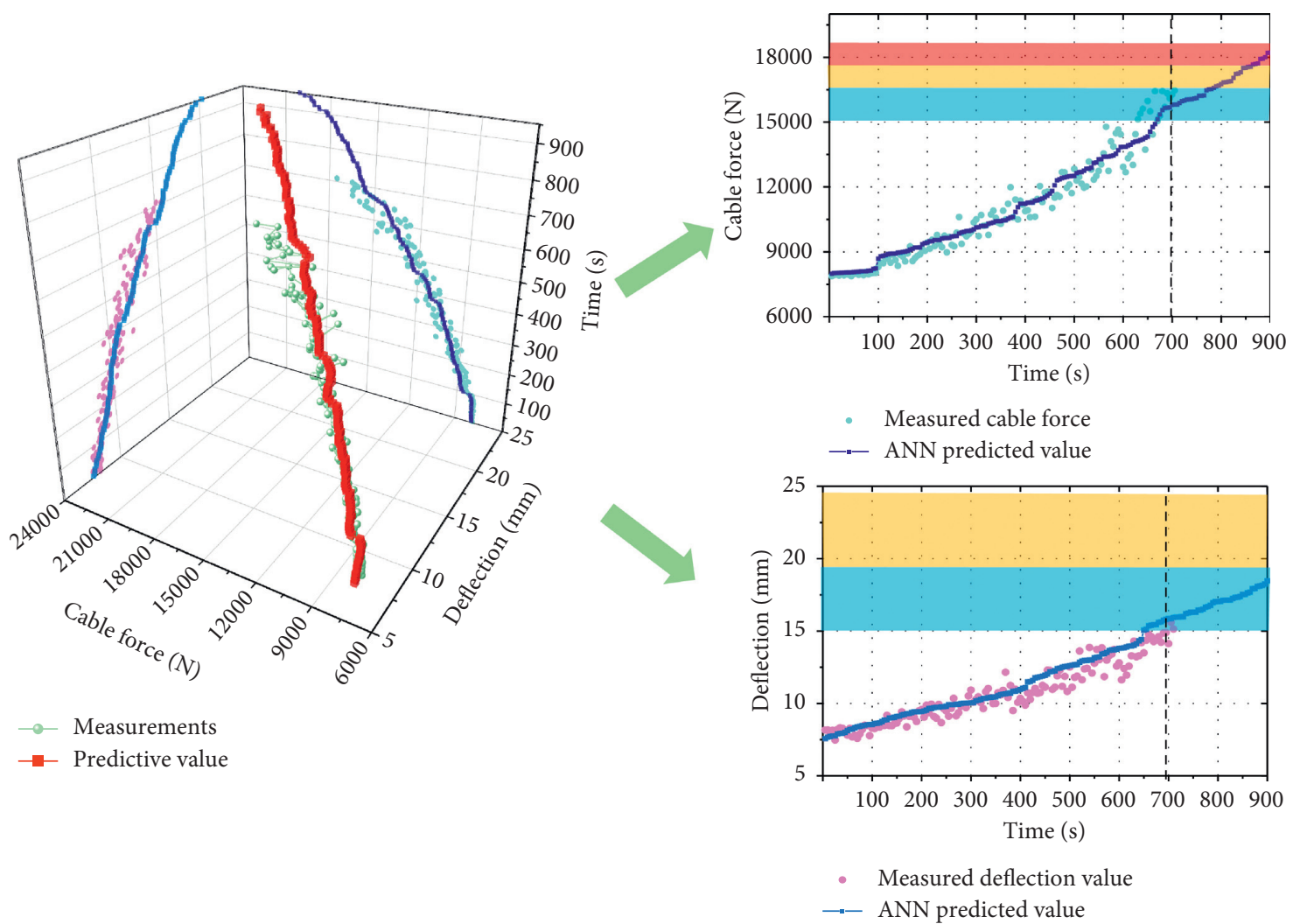

Figure 17: Effect drawing of monitoring and early warning system.

to ensure the safety in the operation and maintenance process. At the same time, it proves the feasibility and effectiveness of the modeling method and improves the informatization and intelligent level of steel structure operation and maintenance system.

\section{Conclusion}

In this paper, a new concept of steel structure operation and maintenance monitoring using the digital twin model is proposed for the first time. Taking the structural safety risk in the cable operation and maintenance stage as the research object, the original data of cable force and displacement parameters are extracted, and the evaluation index system is established; based on the digital twin technology, the mechanical simulation analysis and monitoring data and other information fusion research are carried out to construct the safety risk. The digital twin model realizes real mapping and real-time interaction. The results are as follows:

(1) Combining the concept of digital twin with the concept of steel structure operation and maintenance safety, a framework system of structural health prediction based on digital twin is built from three dimensions: physical space dimension, digital virtual space dimension, and real-time data interaction correlation.

(2) In the operation and maintenance period of steel structure, the digital twin model established by using 3D scanning technology, finite element simulation technology, and intelligent algorithm provides a guarantee for structural safety operation and maintenance early warning and verifies the feasibility of the model.

(3) There is a change in the maintenance decision model from a reactive call-based maintenance decision to a proactive maintenance decision model. The initial model and the digital twin model will continue to iterate. Cumulative damage and repair history are always updated. Through the dual model of physics and analysis, the maintenance team can evaluate the current overall condition of the structure in real time and evaluate the component performance in some cases. It can greatly reduce the response decision-making time of the maintenance team and the occurrence of accidents. In addition, compared with the actual behavior of many other similar steel structures, the management team can formulate some maintenance or reinforcement measures for the structure in time.

(4) Through the actual prestressed steel structure example, the innovative application of digital twin theory in the safety stage of steel structure operation and maintenance can realize the interactive fusion of physical space and virtual space, provide a new method for the safety prediction and risk control of prestressed steel structure in the operation and maintenance stage, and provide theoretical and key technical support for digital twin theory in the intelligent construction industry. 


\section{Data Availability}

The data used to support the findings of this study are available from the corresponding author upon request.

\section{Conflicts of Interest}

The authors declare that they have no conflicts of interest.

\section{Acknowledgments}

This work was supported by the Beijing Natural Science Foundation (no. 8202001). The support is gratefully acknowledged.

\section{References}

[1] F. Zhou, H. Li, Y. Zhu, J. Teng, and J. Ou, "Monitoring and analysis of snow load and its effects on the steel membrane structure of the National Swimming Center," Progress in Building Steel Structures, vol. 13, no. 02, pp. 33-43, 2011, (in Chinese).

[2] A. Zhang, T. Liu, Y. Zhang, and X. Liu, "Research prospects for the innovation of the rapid full-assembly large-span prestressed spatial steel structure system based on intelligent construction," Beijing Industry News, vol. 46, no. 06, pp. 591-603, 2020, (in Chinese).

[3] Y. Wang, Z. Guo, B. Luo, and K. Shi, "Research on the determination method of equivalent pretension of cables for spatial prestressed steel structure," China Civil Engineering Journal, vol. 46, no. 06, pp. 53-61, 2013, (in Chinese).

[4] Q. Zhang, H. Li, H. Yang, and J. Hu, "Development and research of steel structure health monitoring technology," Construction Technology, vol. 41, no. 14, pp. 13-19, 2012, (in Chinese).

[5] H. Zhou and Z. Wang, "The application of BIM technology in the operation and maintenance management of existing bridges," Construction Economy, vol. 37, no. 12, pp. 45-48, 2016, (in Chinese).

[6] C. Li, X. Fan, and C. Li, "Research on E-BIM application of visual monitoring of high-speed railway platform canopy operation and maintenance management system," Railway Transport and Economy, vol. 42, no. 01, pp. 44-49, 2020, (in Chinese).

[7] S. Rikard, W. Kristina, S. Carlson Johan, and L. Lars, "Toward a digital twin for real-time geometry assurance in individualized production," CIRP Annals, vol. 66, no. 1, pp. 137-140, 2017.

[8] G. Warwick, "GE advances analytical maintenance with digital twins," Aviation Week \& Space Technology, pp. 10-19, 2015.

[9] B. Zhang, X. Li, and X. Wan, "From digital twin to digital engineering modeling and simulation enter a new era," Journal of System Simulation, vol. 31, no. 3, p. 369, 2019 (in Chinese).

[10] F. Tao, M. Zhang, J. Cheng et al., "Digital twin workshop: a new paradigm for future workshop," Computer Integrated Manufacturing Systems, vol. 23, no. 1, pp. 1-9, 2017.

[11] F. Tao, Y. Cheng, J. Cheng, and M. Zhang, "Theories and technologies for cyber-physical fusion in digital twin shopfloor," Computer Integrated Manufacturing Systems, vol. 23, no. 8, pp. 1603-1612, 2017.

[12] B. Schleich, N. Anwer, L. Mathieu, and S. Wartzack, "Shaping the digital twin for design and production engineering," CIRP Annals, vol. 66, no. 1, pp. 141-144, 2017.
[13] E. J. Tuegel, A. R. Ingraffea, T. G. Eason, and S. M. Spottswood, "Reengineering aircraft structural life prediction using a digital twin," International Journal of Aerospace Engineering, pp. 1687-5966, 2011.

[14] Y. Ye, Q. Yang, F. Yang, Y. Huo, and S. Meng, "Digital twin for the structural health management of reusable spacecraft: a case study," Engineering Fracture Mechanics, vol. 234, Article ID 107076, 2020.

[15] P. E. Leser, J. E. Warner, W. P. Leser, G. F. Bomarito, J. A. Newman, and J. D. Hochhalter, "A digital twin feasibility study (part II): non-deterministic predictions of fatigue life using in-situ diagnostics and prognostics," Engineering Fracture Mechanics, vol. 229, Article ID 106903, 2020.

[16] A. Mondoro and B. Grisso, "On the integration of SHM and digital twin for the fatigue assessment of naval surface ships," Structural Health Monitoring, vol. 2019, 2019.

[17] Y. Zheng, S. Yang, and H. Cheng, "An application framework of digital twin and its case study," Journal of Ambient Intelligence and Humanized Computing, vol. 10, no. 3, 2018.

[18] P. Yang, M. Zhang, F. Yu, J. Xu, and S. Gao, "Digital twin hospital buildings: an exemplary case study through continuous lifecycle integration," Advances in Civil Engineering, vol. 2020, Article ID 8846667, 13 pages, 2020.

[19] J. Shu, K. Zandi, T. Topac et al., "Automated generation of FE model for digital twin of concrete structures from segmented 3D point cloud," Structural Health Monitoring, vol. 2019, 2019.

[20] K. Zandi, E. H. Ransom, T. Topac et al., "A framework for digital twin of civil infrastructure-challenges \& opportunities," Structural Health Monitoring, vol. 2019, 2019.

[21] S. H. Khajavi, N. H. Motlagh, A. Jaribion, L. C. Werner, and J. Holmstrom, "Digital twin: vision, benefits, boundaries, and creation for buildings," IEEE Access, vol. 7, pp. 147406147419, 2019.

[22] C. Ye, L. Butler, C. Bartek et al., "A digital twin of bridges for structural health monitoring," in 12th International Workshop on Structural Health Monitoring 2019, Stanford University, Stanford, CA, USA, September 2019.

[23] U. T. Tygesen, M. S. Jepsen, J. Vestermark et al., "The true digital twin concept for fatigue re-assessment of marine structures," in International Conference on Offshore Mechanics and Arctic Engineering, American Society of Mechanical Engineers (ASME), Madrid, Spain, June 2018.

[24] K. Sivalingam, M. Sepulveda, M. Spring et al., "A review and methodology development for remaining useful life prediction of offshore fixed and floating wind turbine power converter with digital twin technology perspective," in 2018 2nd International Conference on Green Energy and Applications (ICGEA), pp. 197-204, IEEE, Singapore, March 2018.

[25] C. S. Shim, H. R. Kang, and N. S. Dang, "Digital twin models for maintenance of cable-supported bridges," in International Conference on Smart Infrastructure and Construction 2019 (ICSIC) Driving Data-Informed Decision-Making, pp. 737742, ICE Publishing, Cambridge, UK, July 2019.

[26] K. Lin, Y.-L. Xu, X. Lu, Z. Guan, and J. Li, "Digital twin-based collapse fragility assessment of a long-span cable-stayed bridge under strong earthquakes," Automation in Construction, vol. 123, p. 103547, 2021.

[27] Z. Liu, A. Zhang, and W. Wang, "A framework for an indoor safety management system based on digital twin," Sensors, vol. 20, no. 20, p. 5771, 2020.

[28] Z. Liu, W. Bai, X. Du et al., "Digital twin-based safety evaluation of prestressed steel structure," Advances in Civil Engineering, vol. 2020, Article ID 8888876, 2020. 